\title{
CRESCIMENTO ECONÔMICO, SISTEMA FINANCEIRO E INSTITUIÇÕES
}

\section{ECONOMIC GROWTH, THE FINANCIAL SYSTEM AND INSTITUTIONS}

\section{Luccas Assis Attílio ${ }^{1}$}

\section{Recebido em: 21/08/2016 Aceito em: 19/10/2016}

luccas2014assis@gmail.com
Resumo: Dada a importância do crescimento econômico para a melhora no padrão de vida da sociedade, muitas políticas que propiciam esse resultado são debatidas e empreendidas, entretanto, dado o fracasso de muitas nações em incrementar o produto, o tema se torna relevante e atual. O sistema financeiro é uma parte do sistema econômico que auxilia no crescimento do produto, porém, haja vista as crises financeiras das últimas décadas, torna-se necessário compreender a relação sistema financeiro e crescimento econômico. Todavia, percebe-se que um importante canal que liga essas duas variáveis tem estado afastado do debate: as instituições. Esse artigo é um survey que explora a conexão entre crescimento econômico, sistema financeiro e instituições.

Palavras-chave: Instituições. Crescimento Econômico. Sistema Financeiro.

Abstract: Given the importance of economic growth to improve the standard of living of society, many policies that favor this result are discussed and undertaken, however, given the failure of many nations to increase their products, the topic is relevant and current. The financial system is a part of the economic system that assists output growth, however, given the financial crises in recent decades, it is necessary to understand the relationship financial system and economic growth. However, it is noticed that an important channel connecting these two variables have been far from the debate: the institutions. This article is a survey that explores the connection between economic growth, financial system and institutions.

Keywords: Institutions. Economic Growth. Financial System.

\footnotetext{
${ }^{1}$ Universidade Federal de Ouro Preto - UFOP - Ouro Preto - Minas Gerais - Brasil.
} 


\section{INTRODUÇÃO}

É uma tarefa que data muitos anos tentar compreender o processo de crescimento e desenvolvimento econômico de diferentes nações. Desde as revoluções industriais do século XVIII, que dinamizaram esses fenômenos, o estudo de como desencadear esses processos tem ganhado ênfase nos estudos econômicos.

Fatores como as especificidades de cada país - cultura, tradição, geografia, história - tornam o processo de desenvolvimento como uma experiência única para cada Estado, fazendo com que a tarefa de copiar essa trajetória seja uma difícil e complicada empreitada para outras nações. Além disso, há o contexto em que o crescimento econômico foi deflagrado; no caso dos países conhecidos como Tigres Asiáticos (Coreia do Sul, Taiwan, Cingapura e Hong Kong), por exemplo, essas nações puderam se aproveitar de um menor rigor nas leis de patentes. Deste modo, essas economias usaram o conhecimento de outros países e conseguiram acelerar o crescimento econômico, com elevadas taxas de aumento do produto interno bruto (PIB). Entretanto, esse catch up não ocorreu por causa desse único fator, muitos outros fatores contribuíram para o êxito, como as instituições.

É precisamente nesse ponto que esse artigo tem o objetivo de investigar, procurar relacionar as instituições com os resultados de políticas econômicas perseguidas por algumas economias, assim como explanar por que alguns países possuem instituições que favorecem o crescimento, enquanto outras nações estão sendo prejudicadas por suas instituições.

Para investigar a relação do crescimento econômico com instituições, esse trabalho situará o desenvolvimento do sistema financeiro acoplado às instituições, isto é, conforme as instituições se modificam, qual é a implicação no sistema financeiro circunscrito a essa economia? Como esse processo influi no crescimento econômico?

Muitas nações que lograram um robusto e sustentando crescimento econômico possuíam um sistema financeiro que auxiliou nesse crescimento. Essa relação é historicamente confirmada por alguns autores, como Gerschenkron (1962), que explicou como alguns países europeus aumentaram o produto por meio do desenvolvimento financeiro. Ademais, esse autor também situou como as instituições auxiliaram ou prejudicaram os próprios países. Em particular, o crescimento da Rússia foi retardado por suas instituições.

Não obstante a relação de que instituições facilitem o crescimento do PIB através do sistema financeiro, esse não é o único canal a auxiliar nessa relação, entretanto, será o estudado nesse trabalho.

Portanto, justifica-se esse artigo devido à importância retratada pela literatura entre crescimento econômico, sistema financeiro e instituições. Fazemos aqui um survey de vários trabalhos acadêmicos com o objetivo de realçar essa conexão. Implicitamente estaremos defendendo que a tese de que "one size fits all" não é um bom guia para a formulação de políticas econômicas, dadas as peculiaridades de cada economia. Ademais, esse artigo serve para ajudar a clarear o debate econômico, especialmente o fiscal, que ocorre contemporaneamente na economia brasileira.

Além dessa introdução, o artigo está dividido em outras quatro seções. A próxima seção conceituará o que são instituições; a terceira seção explicará a relação entre instituições e 
crescimento econômico. A quarta tratará de como funciona e desenvolve o sistema financeiro no contexto de diferentes instituições. A quinta seção traçará algumas conclusões sobre o assunto.

\section{CONCEITUANDO AS INSTITUIÇÕES}

O conceito de instituições usado aqui não necessariamente envolve estruturas físicas ou ambientes fechados, pode ser algo mais abstrato, como a cultura de uma nação, tradição, modos de agir, de cooperação ou de efetuar determinada ação com algum objetivo.

Para tanto, como denotam Nelson e Sampat (2001), a racionalidade humana é mais bem compreendida quando entendida como um fenômeno social e cultural. Não se deve procurar compreender os indivíduos de maneira isolada, mas sim, contidos no contexto ao qual habitam, ou seja, nas instituições.

Seguindo esse raciocínio, alguns autores procuram definir o termo instituição. Elster (1989) enfatiza as normas internalizadas na sociedade, às quais englobariam as instituições, porém, de uma forma informal. Usando as normas também, Axelrod (1997) afirma que o mecanismo de punição poderia gerar um resultado esperado se bem estabelecido. Assim, percebe-se que as normas desempenham um importante papel para moldar o funcionamento da sociedade. Cabe ressaltar que essas normas não são homogêneas nos vários países existentes, o que corrobora o fato de que variadas nações possuem diferentes instituições.

Veblen (1899) assinala que instituição é algo conhecido na sociedade e possui um comportamento padrão esperado. De maneira análoga, Hayek (1967) interpreta as instituições como práticas reconhecidas amplamente, entretanto, acopla o conceito de que os indivíduos julgam constantemente essas práticas de acordo com as circunstâncias em que as mesmas são realizadas. Essa definição pode ser interligada com as de Elster (1989) e Axelrod (1997), pois as normas se encaixam nesse conceito tanto formalmente (por exemplo, leis emitidas pelo governo) ou informalmente (cultura, por exemplo).

As instituições podem ser árbitros que equilibrem pressões econômicas, distribuam poder entre os agentes e ofereçam soluções para problemas de coordenação (Hall e Taylor, 1996). Essa definição pode ser estendida para o âmbito internacional sem perda de generalidade, isto é, as instituições equilibram interesses econômicos, distribuem recursos e moldam comportamentos em nível global (Howell e Givan, 2011). Desta maneira, instituição ganha um papel mais ativo na sociedade, funciona como uma referência para os agentes agirem.

North (1990) designa o termo rules of the game para ilustrar instituições, de forma que são essas regras que moldam o comportamento dos agentes. Uma conceituação mais ampla e dinâmica do termo rules of the game pode ser vista no trabalho de Kristensen e Morgan (2012), que colocam as regras como complementares, contraditórias e que sobrepõem umas às outras. Vale salientar o termo regras contraditórias, pois muitas instituições consideradas fracas são caracterizadas por possuírem regras mal estabelecidas e de diferente entendimento pelos agentes. Se tomarmos o governo como uma instituição, como Howell e Givan (2012) fazem, torna-se notável observar como 
muitos países subdesenvolvidos possuem um ambiente de direitos dúbios, como direitos de propriedade, e como esse fator prejudica o crescimento dos mesmos.

Portanto, podem-se entender instituições como sendo o governo, normas, cultura e interação entre os agentes. Crouch (2005) delineia instituições como o conjunto de vários caminhos que a sociedade seguiu. É o resultado de ações passadas, mudanças de regras, ações contínuas. Ao mesmo tempo, instituições podem ser modeladas ao longo do tempo devido a esses caminhos que a sociedade ainda não percorreu, já percorreu ou que percorrerá. É uma interpretação mais dinâmica de instituição, análoga a feita por Howell e Givan (2012).

É na repetição do comportamento que se moldam e caracterizam as instituições, nas regras e no cumprimento delas (North, 1989). Essa interação é circunscrita ao ambiente, que se modifica gradativamente, gerando a cultura do país. Essa mesma cultura também influencia no comportamento dos agentes (Eggertsson, 1999).

De acordo com essas definições, instituições podem ser caracterizadas como fenômenos que demoram a se modificar, tendem à continuidade. São usadas pelos agentes para responder aos desafios atuais.

Não podemos pensar nessas instituições de forma isoladas, uma sem interferir na outra, elas necessitam da interação e complementariedade com outras instituições. Todas as instituições formam o arcabouço pelo qual os agentes devem se basear em suas ações. Por outro lado, esse traço determina que elas se reforcem mutualmente, ou seja, demorem a sofrerem transformações (Hall e Soskice, 2001).

Para finalizar a conceituação de instituições, Nelson e Sampat (2001) separam instituições em dois conceitos: tecnologias sociais, que seriam a interação entre os agentes, a coordenação nas ações; e as tecnologias físicas, que são os equipamentos, máquinas, prédios. A interação entre essas duas instituições formam a sociedade. O interessante dessa análise é que ela separa o que ocorre devido ao progresso material (tecnologia física) e o que ocorre devido ao avanço nas leis, cultura, interação dos agentes (tecnologia social).

Destarte, o termo instituição pode ser entendido como uma ampla gama de fatores tangíveis e intangíveis. Sem deixar de observar o dinamismo e implicações que apresentam para a sociedade. A próxima seção relaciona as instituições com o crescimento econômico.

\section{INSTITUIÇÕES E CRESCIMENTO ECONÔMICO}

Essa seção tratará de citar algumas experiências relacionando instituição com crescimento econômico em alguns países. Como será mostrado, instituições favoráveis ao crescimento econômico, que não obstruam a resolução de conflitos entre os agentes econômicos, bem como garantam a realização de práticas benéficas para o país, são fundamentais para um melhor desempenho do PIB.

Acemoglu e Robinson (2006) analisam a relação entre regimes ditatoriais e desempenho econômico. Como mostraram, esses regimes tendem a seguir políticas perniciosas para o crescimento do produto, pois os líderes de ditaduras geralmente seguem práticas que aumentem o 
consumo pessoal ou a sobrevivência política deles. A conclusão é de que quando o país possua instituições fortes e relativamente independentes, essas políticas prejudiciais ao crescimento são mitigadas, consequentemente, o país pode usufruir elevadas taxas de crescimento econômico.

Seguindo trabalhos com regimes ditatoriais, Przeworski et al. (2000) concluem que a maioria das experiências malogradas de crescimento econômico tem vindo de países ditatoriais, entretanto, ditaturas asiáticas mostraram êxito econômico. Novamente, instituições parecem desempenhar o papel principal para explicar essa disparidade (Knutsen, 2010), pois não se achou relação significativa entre democracia e crescimento econômico no continente asiático.

É intuitivo analisar que instituições fortes e independentes amenizem os danos de políticas econômicas formuladas por líderes ditatoriais em benefício próprio. Essas instituições limitam a discricionariedade do poder desses líderes, assim como podem reivindicar por um melhor direcionamento dessa política.

Analisando o regime oposto, a democracia, suas instituições são caracterizadas por maior participação do povo nas decisões governamentais, assim como maior transparência para as decisões de seus líderes. Em contrapartida, os políticos que estão no poder possuem menor grau de manobra para perseguirem determinadas políticas que poderiam gerar um maior crescimento econômico (políticas pouco populares). Em ambos os regimes é fundamental a participação das instituições de forma a gerar um resultado econômico.

Lipsey (2009) explica que as instituições foram fundamentais para que a revolução industrial ocorresse na Europa e não em outro lugar. Ele argumenta que outras localizações no globo possuíam condições para inovar, entretanto, não contavam com instituições que efetuassem o direcionamento correto dos incentivos e que ajudassem a acumular conhecimento científico. É justamente nesse ponto que a Europa se sobressaiu em detrimento das outras nações. Um exemplo de instituição europeia foram as universidades medievais, que não foram inventadas pelos europeus (Makdisi, 1981), porém, eles souberam canalizar o conhecimento existente e transformá-lo em insumo através dessas instituições para gerar as tecnologias que permitiriam as revoluções industriais.

Instituição não é um fenômeno estático, pelo contrário, é dinâmico. Não basta somente possuir uma instituição, deve-se moldá-la de modo a se tornar apropriada para o crescimento do país.

Instituições podem reduzir os custos de transações para os agentes; o caso citado sobre a revolução industrial ilustra esse ponto. Ao melhorar a instituição universidade, os europeus lograram acumular conhecimento científico, ou seja, reduziram os custos de inovar futuramente (Hall, 2007).

Empiricamente, um exemplo de país que soube transformar suas instituições de modo a crescer economicamente foi a Dinamarca, que sofreu com alta inflação, déficits públicos e alto desemprego no fim do fordismo, por volta da década de 1970. Antigas instituições não mais se adequavam ao atual ambiente de mudanças, assim, elas começaram a se alterar. Algumas regras e costumes foram abandonados. Porém, as mudanças institucionais começaram pelos agentes, que passaram a alterar suas formas de agir e cooperar. A mudança ocorreu primeiramente a nível microeconômico e depois chegou ao nível macroeconômico. Atualmente, o país se adaptou para o ambiente de crescente competitividade internacional. Os recursos institucionais ajudaram os atores a moldar novas instituições. Inovações passaram a ocorrer. A Dinamarca possuía bons legados 
institucionais, deste modo, construiu as novas instituições com base nas qualidades das antigas (Kristensen e Morgan, 2012).

Esse último exemplo elucida os termos usados sobre instituições; sofreram modificações quando eram obsoletas ao crescimento (dinamismo), ao se modificarem adequadamente, permitiram que a economia voltasse a funcionar melhor (reduziram os custos de transações) e boas instituições ajudaram a moldar as novas (é o que os autores chamam de recursos institucionais). Cabe enfatizar o legado institucional que serve de base para melhorias institucionais e como ponto de referência para os agentes buscarem os ajustes necessários. A Dinamarca utilizou-se justamente desse recurso para superar as adversidades nas quais se encontrava.

Em um mundo que sofre rápidas modificações, as instituições devem ser modeladas de forma a incorporar as características contemporâneas. Não é exagero afirmar que instituições estáticas podem decrescer a competitividade dos países e prejudicar o crescimento econômico.

Países da Europa Ocidental desfrutaram de altas taxas de crescimento e inovação no passado devido ao fato de que desenvolveram eficientes mecanismos de direito de propriedade, de contratos formais, garantias e elaborado sistema de monitoramento. A estrutura institucional é eficiente (North, 1989). North (1989) associa o sucesso das colônias da América do Norte com o fracasso das colônias da América do Sul devido às instituições. Elas causaram divergências entre os países tanto economicamente quanto politicamente pela forma como foram construídas, modificadas e mantidas.

Juntando os casos dos países europeus e da América do Norte e contrastando-os com a América do Sul ou outros países menos desenvolvidos, nota-se que o fator institucional pode desempenhar a função de facilitar o crescimento econômico ou atrasá-lo. Mais ainda, a história do país pode melhorar ou piorar as instituições, pois elas são construídas através de ações tomadas no passado. North (1989) chama a atenção para grupos de interesse, que podem deturpar a eficiência das instituições na medida em que eles podem usar do seu poder político ou econômico para manter o atual funcionamento da instituição de modo a beneficiá-los. Nesse caso, o aprimoramento e ajuste gradual das instituições seriam prejudicados.

Essa análise entre países pode ser entendida em um único país em específico, ou seja, um determinado país pode possuir ao mesmo tempo favoráveis e desfavoráveis instituições. Freeman e Perez (1988) explicam que a mudança de setor líder na indústria de um mesmo país pode ser entendida pelas instituições, que são capazes de absorver tecnologias que levam a esse resultado, e outras instituições incapazes de fazer o mesmo.

Deste modo, há uma 'luta' institucional dentro do país. Entretanto, esse quadro também não é estático, modificações ao longo do tempo tendem a alterar as instituições. No final do século XIX e na primeira metade do século XX, a produção em massa dos EUA se aproveitou de crescentes ganhos de produtividade, inovações tecnológicas e um grande mercado consumidor. Todavia, teve de surgirem novas instituições (novos modos de organização de trabalho, rotina, novas relações empregador-empregado, novas tecnologias sociais e físicas), para que o processo pudesse se corporificar (Nelson e Sampat, 2001). Para a evolução econômica do país, necessita-se de novas 
tecnologias, que, por sua vez, irão necessitar de novas leis, regulamentações, rotinas e hábitos para serem assimiladas, ou seja, novas instituições.

Como ressaltado nessa seção, mudança institucional deve ser entendida como um processo dinâmico. Ferner e Hyman (1992) afirmam que mudanças institucionais decorrem de alterações na economia; nesse caso, instituição se alteraria devido ao fator externo (exógeno). Por outro lado, Campbell (2004) denota que agentes vinculados em algumas instituições podem causar alterações nelas através de suas ações, ou seja, a mudança seria endógena. Streeck e Thelen (2005) enfatizam que alterações institucionais decorrem mais de fatores endógenos do que exógenos. Um resultado seria que mesmo instituições que trabalhem à margem, podem evoluir de modo a ganharem importância no futuro, seja por meio exógeno ou endógeno.

Nelson (2008) chama a atenção para a dificuldade de se avaliar alguma instituição. Como dizer que ela é boa ou ruim? Um corolário dessa questão seria: qual instituição reformar? Dado que é difícil avaliá-la, obtém-se um empecilho: saber quais instituições devem ser melhoradas. Esse questionamento é válido, pois segundo o autor, inovações tecnológicas ocorrem mais rapidamente do que mudanças institucionais. A instituição, caso fique demasiadamente inalterada, pode atrasar os avanços tecnológicos e, por consequência, do produto (Niosi, 2010).

Em suma, é recomendável que o país possua bons aparatos institucionais para obter uma trajetória de crescimento econômico sustentada. Da mesma forma, realizado esse primeiro objetivo, deve-se continuar no esforço de aprimorar as instituições e adequá-las às mudanças do ambiente econômico para não deixá-las se tornarem em obstáculos ao crescimento. Não é um processo de realização trivial porque as instituições são complexas, difíceis de serem mensuradas e de demorada transformação em geral - e nem sempre o resultado de suas alterações é o esperado. Nas palavras de Nelson e Sampat (2001, p. 51) "the process of institutional change involves lots of trial, failure, try again, learn from mistakes".

\section{INSTITUIÇÕES E O SISTEMA FINANCEIRO}

Visto a relação da instituição com crescimento econômico, a intenção dessa seção é mostrar como a instituição afeta o sistema financeiro, e assim verificar o seu impacto no produto de algumas economias. Como as instituições, o sistema financeiro também é caracterizado por ser dinâmico, sofrer choques que podem alterar o seu desenvolvimento e assim moldá-lo de diferentes formas.

Nas recentes décadas, a principal alteração que o sistema financeiro atravessou foi a liberalização financeira. Esse fenômeno foi caracterizado por um conjunto de políticas de forma a abrir o sistema financeiro de economias antes fechadas financeiramente. O objetivo foi tirá-las da estagnação econômica, alta inflação e crescentes déficits nas contas internas e externas. Esse processo ocorreu a partir do final da década de 1970.

O fato é que essa nova guinada na política financeira acarretou profundas mudanças nas instituições dos países. Anteriormente a essa alteração, as instituições foram construídas baseadas na repressão financeira (países que tinham o sistema financeiro não liberalizado). Essa mudança em muitos países adveio de forma abrupta, tornando difícil que as instituições estabelecidas se 
adaptassem de forma adequada. Assim, nas experiências que serão citadas a seguir, o fracasso de tais liberalizações financeiras pode em grande parte ser devido ao não ajustamento correto das instituições. Talvez não por culpa dos agentes que faziam parte delas, mas sim devido ao curto intervalo de tempo para que elas pudessem se modificar e adaptar ao novo ambiente econômico circunscrito a elas.

O Chile liberalizou sua economia nos anos finais de 1970. Embora o país tenha recebido volumosos influxos de capitais, os resultados dessa política foram desanimadores. Financiamentos de longo prazo não surgiram, a corrupção se alastrou, a poupança decresceu e o PIB caiu (DiazAlejandro, 1985).

Outro país a sofrer com crise após liberalização financeira foi o México em 1994. Inicialmente o país foi visto como um caso de sucesso, recebendo significativos capitais. Entretanto, o país não possuía fundamentos econômicos que justificassem essa maciça entrada de capitais. A especulação tomou conta da economia e, por fim, o México entrou em uma crise que afetou outros países (Singh e Weisse, 1998).

Outra severa crise foi a asiática em 1997, quando o capitalismo clientelista, insider lending e a especulação foram práticas perniciosas que alguns países sofreram. No final, o resultado foi análogo às crises do México e Chile, com os países entrando em recessões e capitais saindo deles.

Assim, analisando essas crises, percebe-se que as instituições sofreram para se adequarem ao novo ambiente econômico. Uma evidência disso é a prática da corrupção, que continuou no mesmo nível, embora de diferentes formas (Chang e Grabel, 2004). Um país que se caracterizava por possuir um alto nível de corrupção na esteira da repressão financeira, continuou a praticar práticas fraudulentas. E essa tendência minou os bons resultados que poderiam advir da liberalização financeira. Cabe ressaltar que tentando superar essa adversidade que ficou exposta pelas crises de liberalização, surgiu a defesa por melhores aparatos regulatórios nas economias liberalizadas.

Dessa maneira, as instituições que sofreram o choque da liberalização, agora deviam se adaptar a algumas práticas regulatórias. Essa tendência voltou a acirrar o debate acadêmico atual com recente crise financeira, a dos EUA em 2007, quando o banco de investimento Lehman Brother faliu. O pânico atravessou vários mercados financeiros mundiais e muitas práticas de caráter duvidoso apareceram.

A despeito das crises citadas anteriormente, essa não ocorreu devido a liberalização financeira em $\mathrm{si}$, pois os EUA são caracteristicamente uma economia com o sistema financeiro liberalizado. A questão foi outra, foi a respeito da regulação financeira (Dymski, 2012).

Observa-se que pouco se preocupou com as instituições dos países quando se defendeu a liberalização financeira. Políticas semelhantes foram receitadas para países díspares em termos institucionais, desconsiderando fatores como a cultura, interação dos agentes, leis e o governo.

A eclosão da crise de 2007 trouxe de volta o conceito da política de too big to fail, que foi criada em 1984 pelos EUA, para salvar grandes bancos de possíveis falências. Falências que representariam um enorme fardo para o sistema financeiro americano e mundial. $O$ interessante desse ponto não é questionar sua validez, eficiência e legitimidade, pelo contrário, é o ressurgimento dessa instituição. Analogamente na seção que conceituou o termo instituição, Crouch (2005) disse 
que instituição é o conjunto de caminhos que a sociedade percorreu, sendo que não necessariamente um caminho que já foi percorrido não será mais usado para moldar alguma nova instituição ou trazer uma instituição de importância secundária para a relevância institucional. Nesse caso, a instituição too big to fail ficou anos sem importância crucial, entretanto, reapareceu com o deflagrar da crise de 2007.

Outros eventos históricos também desempenharam modificações nas instituições financeiras. Na grande depressão de 1930, várias firmas financeiras dos EUA faliram, enquanto na América latina poucas dessas firmas sofreram em demasia. A resposta para essa questão, de acordo com DiazAlejandro (1985), é que a maioria das firmas latinas eram de propriedade estatal.

Conforme a Era de Ouro do capitalismo (1945-1970) chegava ao seu fim devido a choques do petróleo, declínio econômico de vários países e questionamentos de suas políticas econômicas seguidas, as regulações bancárias foram se tornando mais frouxas paulatinamente (Glyn et al., 1998).

De acordo com essa premissa, as instituições respondem aos diferentes desafios dependendo da forma como são estabelecidas. No caso citado por Diaz-Alejandro (1985), o fato de que muitas firmas fossem públicas acabou por ajudar na sobrevivência.

O sistema financeiro é um canal pelo qual os países podem recrudescer o crescimento econômico, entretanto, o mercado financeiro está sujeito a falhas, seja de informações ou regulamentações. O fato é que se usado de forma eficiente pode potencializar o PIB das economias. Muitas economias que liberalizaram suas finanças possuíam previamente algum nível de práticas fraudulentas, assim, é difícil imaginar que apenas com a abertura tais estratégias desapareceriam, uma vez que elas fazem parte das instituições do Estado, e como dito anteriormente, mudanças desse nível em instituições levam tempo - se é que ocorrem, dado que instituições podem se tornar estáticas e obsoletas. Um exemplo disso foi a crise asiática de 1997, na qual alguns países contavam com regulamentações prevenindo a prática de insider lending, todavia, falhas na regulamentação deixaram que bancos fizessem uso desse instrumento (Rahman, 1998). Esse caso ilustra a ideia sobre a redução da corrupção sob a égide da liberalização, pois países asiáticos contavam com mecanismos regulatórios contra fraudes, e mesmo abrindo suas economias falharam no quesito redução dessas atividades.

Para finalizar essa seção, a conclusão é a de que instituições não podem ser ignoradas ao formular políticas econômicas no país. Grande parte da eficácia dessa política dependerá de sua receptibilidade pelas instituições da economia. A liberalização financeira foi defendida supondo que diferentes países possuíssem instituições homogêneas - o que não é respaldado pela experiência histórica. Como as evidências mostraram várias crises, processos de reestruturação e debates em torno de como regular as economias ocorreram (Johnson e Kwak, 2010; Kroszner e Shiller, 2011), porém, falta um debate mais centrado a respeito das instituições e sobre o seu papel no melhor funcionamento do sistema financeiro. 


\section{CONCLUSÃO}

O tema crescimento econômico sempre está em pauta em diferentes épocas e contemporaneamente isso não é exceção. Após a crise financeira dos EUA em 2007, o rendimento econômico claudicante da União Europeia (EU) e a perda de dinamismo de algumas economias emergentes, como a do Brasil, esse tópico ganhou relevância.

O que falta para melhorar esse debate é um maior enfoque nas especificidades de cada país. Não basta apenas pensar na política monetária, fiscal, cambial ou financeira; devemos pensar na cultura, na interação dos agentes, burocracia, leis, sistemas de proteção ao consumidor, informalidade - ou seja, nas instituições.

Como ficou claro na seção três, instituições possuem uma forte correlação com o crescimento econômico. A seção quatro demonstrou um canal por meio do qual as instituições afetam o produto, que é o sistema financeiro, que está em crescente expansão atualmente, haja vista os recentes acontecimentos globais. Porém, é essencial entender o que é instituição, e a seção dois tratou exclusivamente desse assunto. Compreender o seu desenvolvimento, perceber como elas se modificam e passar a incorporá-las nos impactos de diferentes políticas econômicas pode ser a resposta para determinadas economias voltarem para a trajetória de crescimento econômico sustentado.

Nesse ponto, podemos citar o Brasil, que passa por uma severa crise econômica, em especial, na esfera fiscal. Vemos no debate a defesa de variados tipos de políticas, mas pouco se observa uma análise sobre as especificidades do país, em como as instituições podem reagir caso uma nova política seja empreendida. As consequências de importar modelos de políticas de outros países, notadamente as nações desenvolvidas, envolve riscos significativos para a economia brasileira, uma vez que nossa realidade é diferente. Sobretudo, nossas instituições são notadamente distintas daqueles.

Estudos do CEPE [ISSN 1982-6729]. Santa Cruz do Sul, n. 44, p. 5-16, jul./dez. 2016. 


\section{REFERÊNCIAS}

ACEMOLGU, D. e ROBINSON, J. A. Economic backwardness in political perspective. American Political Science Review, vol. 100, n. 1, p. 115-131, 2006.

AXELROD, R. The Complexity of Cooperation. Princeton University Press, Princeton, NJ, 1997.

CHANG, H. J. e GRABEL, I.. Reclaiming Development: An Alternative Economic Policy Manual, London: Zed Books, 2004.

CROUCH, C. Capitalist Diversity and Change. Oxford: Oxford University Press, 2005.

DIAZ-ALEJANDRO, C. F., Goodbye Financial Repression, Hello Financial Crash. Journal of Development Economics, vol.19, n. 1, p. 1-24, 1985.

DYMSKI, G. A. O Gênio Fora da Garrafa: A evolução da Política Too Big to Fail e a Estratégia Bancária dos Estados Unidos. In: CINTRA, M. e GOMES, K. (ed.) As transformações no sistema financeiro internacional. Brasília: Instituto de Pesquisa Econômica Aplicada (IPEA), 2012, p. 177244.

EGGERTSSON, T. The Emergence of Norms in Economics - With Special Reference to Economic Development. Max Plank Institute for Research into Economic Systems, unpublished manuscript, 1999.

ELSTER, J. The Cement of Society. Cambridge University Press, Cambridge, MA, 1989.

FERNER, A. e HYMAN, R. Industrial Relations in the New Europe. Oxford: Blackwell, 1992.

FREEMAN, C. e PEREZ, C. 1988. Structural crises of adjustment, business cycles, and investment behavior. In: DOSI et al. (ed.), Technical Change and Economic Theory. Pinter Press, London, 1988.

GERSCHENKRON, A. Economic Backwardness in Historical Perspective. Harvard University Press, Cambridge, MA, 1962.

GLYN, A. et al. The rise and fall of the golden age. Helsinki: World Institute for Development Economics Research of the United Nations University. Wider Working Papers, n. 43, 1988.

HALL, P. A. The Evolution of Varieties of Capitalism in Europe. In: HANCKE, M. e RHODES, M. (ed.) Beyond Varieties of Capitalism: Conflict, Contradictions and Complementarities in the European Economy, Oxford: Oxford University Press, 2007, p. 39-85.

HALL, P. e SOSKICE, D. E. Varieties of Capitalism: The Institutional Foundations of Comparative Advantage. New York: Oxford University Press, 2001.

HALL, P. e TAYLOR, R. Political science and the three institutionalisms. Political Studies, vol. 44, n. 5, p. 936-57, 1996.

HAYEK, F. Studies in Philosophy, Politics, and Economics. Routledge \& Kegan Paul, London, 1967.

HOWELL, C e GIVAN, K. R. Rethinking Institutions and Institutional Change in European Industrial Relation. British Journal of Industrial Relations, vol. 42, n. 2, p. 231-255, 2011.

JOHNSON, S. e KWAK, J. The 13 bankers. New York: Pantheon, 2010.

KROSZNER, R. S. e SHILLER, R. J. Reforming US financial markets: reflections before and beyond Dodd-Frank. Cambridge: MIT Press, 2011.

KNUTSEN, C. H. Investigating the Lee thesis: How bad is democracy for Asian economies. European Political Science Review, vol. 2, n. 3, p. 451-473, 2010. 
KRISTENSEN, H. P. e MORGAN, G. From Institutional Change to Experimentalist Institutions. Industrial Relations, vol. 51, n. 51, 2012.

LIPSEY, G. R. Economic growth related to mutually interdependent institutions and technology. Journal of Institutional Economics, vol. 5, n. 3, p. 259-288, 2009.

MAKDISI, G. The Rise of Colleges: Institutions of Learning in Islam and the West. Edinburgh: Edinburgh University Press, 1981.

NELSON, R. R. What enables rapid economic progress: What are the needed institutions? Research Policy, vol. 37, p. 1-11, 2008.

NELSON, R. R. e SAMPAT, N. B. Making sense of institutions as a factor shaping economic performance. Journal of Economic Behavior \& Organization, vol. 44, p. 31-54, 2001.

NIOSI, J. Rethinking science, technology and innovation (STI) institutions in developing countries. Innovation: Management, policy \& practice, vol. 12, n. 3, p. 250-268, 2010.

NORTH, D. Institutions and Economic Growth: An Historical Introduction. World Development, vol. 17, n. 9, p. 1319-1332, 1989.

NORTH, D. Institutions, Institutional Change and Economic Performance. Cambridge: Cambridge University Press, 1990.

PRZEWORSKI, A. et al. Democracy and development: Political institutions and well-being in the world, 1950-1990. New York: Cambridge University Press, 2000.

RAHMAN, M. Z. The Role of Accounting and Disclosure Standards in the East Asian Financial Crisis: Lessons Learned, mimeo, Geneva: UNCTAD.

SINGH, A. e WEISSE, B.A. Emerging Stock Markets, Portfolio Capital Flows and Long-term economic Growth: Micro and Macroeconomic Perspectives. World Development. vol. 26, n. 4, p. 607-622, 1998.

STREECK, W. e THELEN, K. Beyond Continuity: Institutional Change in Advanced Political Economies. Oxford: Oxford University Press, 2005.

VEBLEN, T. The Theory of the Leisure Class: An Economic Study of Institutions. Macmillian, New York, 1899. 